\title{
Caroço de algodão em dietas à base de palma forrageira para vacas leiteiras: síntese de proteína microbiana ${ }^{1}$
}

\author{
Airon Aparecido Silva de Melo $^{2}$, Marcelo de Andrade Ferreira ${ }^{3}$, Antonia Sherlânea Chaves \\ Véras $^{3}$, Mário de Andrade Lira ${ }^{3}$, Luiz Evandro Lima ${ }^{4}$, Ricardo Alexandre Silva Pessoa ${ }^{5}$ \\ ${ }^{1}$ Parte da tese do primeiro autor. Parcialmente financiada pelo CNPq e acordo IPA/UFRPE. \\ 2 Unidade Acadêmica de Garanhuns/UFRPE. \\ ${ }^{3}$ Departamento de Zootecnia/UFRPE, Bolsista CNPq. \\ 4 IPA. \\ 5 Programa de Doutorado Integrado em Zootecnia - UFRPE/UFPB/UFC.
}

RESUMO - Objetivou-se avaliar o efeito da inclusão de caroço de algodão em substituição parcial à silagem de sorgo e ao farelo de soja em dietas à base de palma forrageira sobre a produção de proteína microbiana, a eficiência de síntese de proteína microbiana e as concentrações de uréia na urina e de uréia e N-uréia no plasma e no leite de vacas holandesas em lactação. Foram utilizados cinco animais aos 50 dias de lactação, distribuídos em quadrado latino $5 \times 5$. Os tratamentos consistiram de cinco níveis $(0,0 ; 6,25 ; 12,50 ; 18,75$ e 25,00\%) de inclusão de caroço de algodão na MS da dieta. A inclusão de caroço de algodão na dieta não influenciou a síntese de nitrogênio ou proteína microbiana, cujos valores médios foram 295,08 e 1.844,27 g/dia, respectivamente. As eficiências de síntese de nitrogênio e proteína microbiana diminuíram linearmente, em proporções de 0,30 e 1,43 g para cada $1 \%$ de caroço de algodão na dieta, respectivamente. Os níveis de uréia na urina e de uréia e N-uréia no plasma e no leite não foram afetados pela inclusão de caroço de algodão na dieta. Portanto, em dietas à base de palma forrageira, a inclusão de caroço de algodão em níveis de até $25 \%$ da MS não interfere na síntese de proteína microbiana e nas concentrações de uréia.

Palavras-chave: amostra spot, creatinina, derivados de purina, semi-árido

\section{Whole cottonseed in forage cactus based diets: synthesis of microbial protein}

\begin{abstract}
The objective of this trial was to investigate the effects of partial replacement of sorghum silage and soybean meal with whole cottonseed on microbial protein synthesis and efficiency and nitrogen metabolism in lactating Holstein cows receiving forage cactus based diets. Five animals were randomly assigned to a $5 \times 5$ Latin square design and were fed diets containing (\% of DM): $0.0,6.25,12.50,18.75$, and $25.00 \%$ of whole cottonseed. Inclusion of whole cottonseed in the diet did not affect microbial nitrogen and microbial protein synthesis, which averaged 295.08 and $1844.27 \mathrm{~g} / \mathrm{day}$, respectively. Microbial protein synthesis and microbial nitrogen efficiency decreased linearly by 0.30 and $1.43 \mathrm{~g}$ per each $1 \%$ inclusion of whole cottonseed in the diet. Urinary urea and concentration of urea and urea-N in plasma and milk were not affected by increasing the levels of dietary whole cottonseed. It can be concluded that the inclusion of up to $25 \%$ of whole cottonseed (\% of diet DM) had no detrimental effects on microbial protein synthesis and $\mathrm{N}$ utilization in lactating cows fed forage cactus based diets.
\end{abstract}

Key Words: creatinine, purine derivatives, spot sampling, semi-arid

\section{Introdução}

A maximização da produção em vacas de alto potencial pode ser limitada pela suplementação de energia e proteína metabolizável. A proteína metabolizável pode ser constituída de três fontes: proteína sintetizada no rúmen, proteína dietética que escapa da degradação ruminal e proteína endógena (NRC, 2001).

A proteína microbiana tem impacto significativo na quantidade e qualidade da proteína metabolizável absorvida no intestino delgado, pois a proteína dietética combaixa degradabilidade ruminal pode ter menor digestibilidade que a proteína microbiana no intestino delgado, que, por sua vez, apresenta perfil de aminoácidos próximo ao requerido pelo animal (O’Connor et al., 1993). Portanto, dietas que maximizam a produção de proteína microbiana podem incrementar a produção de leite.

A mensuração contínua da suplementação protéica microbiana pode ser uma importante área de estudo na nutrição protéica de ruminantes (Valadares et al., 1999). A 
estimativa da contribuição de proteína microbiana que chega ao intestino e o fluxo de incorporação da proteína nos sistemas avaliados (NCR e AFRC) são bastante alterados pelo uso e pelas diferentes condições de campo.

A suplementação de proteína microbiana para o animal, por unidade de alimento ingerido, usualmente é expressa em grama de nitrogênio microbiano por quilograma de matéria orgânica fermentada no rúmen (gNmic/kg MODR). Segundo o ARC (1984), esta produção pode variar de 14 a $60 \mathrm{gNmic} / \mathrm{kg}$ MODR, com média de $32 \mathrm{~g}$. O NRC (2001) assumiu produção média de $130 \mathrm{~g}$ de PB microbiana (PBmic) para cada kg de nutriente digestível total (NDT) consumido, podendo haver variação de 53 a $140 \mathrm{~g}$ PBmic/kg NDT. Essas variações podem ser influenciadas por vários fatores relacionados à dieta ou ao ambiente ruminal. No entanto, o efeito de muitos desses fatores não tem sido demonstrado ou definido quantitativamente (Chen \& Gomes, 1995) e merecem, portanto, mais estudos para determinação da síntese de proteína microbiana.

De acordo com Clark et al. (1992), entre os diversos fatores, os que mais afetam o crescimento microbiano são energia e nitrogênio, no entanto, a suplementação de gordura na dieta, tanto em quantidade superior à de $3 \%$ normalmente encontrada na dieta de ruminantes como as diferentes fontes empregadas (saturada ou insaturada), pode interromper a fermentação microbiana e diminuir a digestão da fibra, mudando a proporção de ácidos graxos voláteis, ou interferir no metabolismo de nitrogênio no rúmen (Jenkins, 1993).

Diversos métodos in vivo são empregados para quantificar a síntese de proteína microbiana ruminal, incluind o os marcadores internos (bases purinas e ácido 2,6 diaminopimélico, DAPA) e externos, como os isótopos $\mathrm{N}^{15}$, $\mathrm{S}^{32}$ e $\mathrm{P}^{32}$ (Broderick \& Menchen, 1992). Segundo Chen \& Gomes (1995), esses métodos envolvem complicados procedimentos para mensurações do fluxo da digesta e requerem o uso de animais fistulados no abomaso, o que dificulta, na prática, a condução de estudos in vivo para determinação da síntese de proteína microbiana.

O uso da excreção urinária de derivados de purina (DP) como marcador metabólico da síntese microbiana em ruminantes foi proposto por Topp \& Elliott (1965), citados por Valadares et al. (1999). No entanto, maiores progressos no seu estabelecimento como método relacionando a excreção de DP e a produção de nitrogênio microbiano só foram estabelecidos recentemente (Silva et al., 2001).

O método baseado na mensuração dos DP na urina supera em alguns aspectos os métodos anteriores. É simples, pois requer apenas coleta total de urina, portanto, um método não-invasivo (não exige o uso de animais cirurgica- mente preparados) e tem um potencial para, no futuro, ser mais simplificado com o uso de outras condições (Chen \& Gomes, 1995). Por esse método de determinação da excreção urinária de derivados de purina, admite-se que os ácidos nucléicos que chegam ao duodeno são de origem predominantemente microbiana, que, após a digestão intestinal e absorção, são proporcionalmente recuperados na urina como alantoína, xantina, hipoxantina e ácido úrico (Peres et al., 1996). Segundo Chen \& Gomes (1992), na urina de bovinos são encontradas apenas alantoína e ácido úrico, em proporção média de 80 a $85 \%$ e 20 a $15 \%$, respectivamente, em virtude da intensa atividade da xantina oxidase no sangue e nos tecidos, que irá converter xantina e hipoxantina a ácido úrico.

No entanto, o método para estimar a produção de proteína microbiana com base na excreção de DP apresenta ainda o inconveniente da necessidade de coleta total de urina, visto que o tempo de coleta para reduzir os erros, em virtude da variação na produção de urina, deve ser de no mínimo cinco dias de coleta (Chen \& Gomes, 1992). Dados da literatura comprovam que esse período tem variações de 24 horas até nove dias. Portanto, além de trabalhoso, é bastante desconfortável para o animal e pode interferir em outras variáveis. Segundo Oliveira et al. (2001), é importante o desenvolvimento de metodologias que permitam o menor tempo possível de coleta de urina ou até mesmo que torne desnecessária a coleta total, como as estimativas baseadas na excreção de creatinina utilizando coleta spot de urina.

Existem na literatura várias citações de que a excreção de creatinina é uma função constante do peso vivo (Orskov \& Mcleod, 1982; Valadares et al., 1997; Valadares et al., 1999; Rennó et al., 2000). Neste sentido, parece possível a utilização da excreção de creatinina como indicador para estimativa do volume urinário, o que, segundo Chen \& Gomes (1995), pode permitir a estimativa da excreção de derivados de purina e de outros compostos nitrogenados sem coleta total de urina.

Com o intuito de confirmar a eficiência do uso de creatinina como indicador para estimativa do volume urinário, Valadares et al. (1999) conduziram experimento com vacas holandesas de alta produção, em lactação, alimentadas com dietas com 20, 50 e $65 \%$ de concentrado e não observaram diferença significativa entre a excreção de creatinina pelo método de coleta total de urina e a estimativa na amostra spot de urina, comprovando diferença apenas para o nível de $35 \%$ de concentrado.

Oliveira et al. (2001) e Silva et al. (2001), ao testarem níveis de nitrogênio não-protéico na dieta de vacas holandesas e Holando-zebu, respectivamente, também não 
notaram dife rença significativa entre o volume urinário obtido pela coleta total e o estimado pela excreção de creatinina na amostra spot de urina. Com base nos resultados obtidos, esses autores recomendaram que o volume urinário pode ser estimado a partir de amostras spot de urina.

A absorção de amônia através da parede do rúmen é a principal rota para a amônia que não foi utilizada pelos microrganismos. Essa amônia é removida da circulação pelo fígado, onde entra no ciclo da uréia (Visek, 1979), sendo eliminada do organismo de mamíferos. Quando sua concentração no rúmen supera sua utilização pelos microrganismos, encontra-se em elevada concentração no rúmen, au mentando conseqüentemente a excreção de uréia e resultando em perda de nitrogênio (Russell et al., 1992).

Segundo Broderick (1995), a elevada concentração de uréia no plasma está relacionada à utilização ineficiente da proteína. A uréia sangüínea atravessa o epitélio da glândula mamária para o leite e, nesse caso, tem-se verificado correlação positiva entre a concentração de n-uréia no leite (NUL) e a de n-uréia no plasma (NUP), podendo-se utilizar, portanto, o NUL e NUP como indicadores do metabolismo protéico em vacas em lactação (Roseler et al., 1993).

Este estudo foi realizado com os objetivos de avaliar os efeitos da inclusão de caroço de algodão na dieta de vacas holandesas em lactação sobre a estimativa da produção e a eficiência de síntese de proteína microbiana e estudar as concentrações de uréia na urina, uréia e N-uréia no plasma e no leite.

\section{Material e Métodos}

O experimento foi conduzido na Estação Experimental de São Bento do Una-PE, pertencente à Empresa Pernambucana de Pesquisa em Agropecuária - IPA, no período de agosto a novembro de 2002. A cidade de São Bento do Una está localizada na mesorregião do Agreste Setentrional e na microrregião do Vale do Ipojuca, tendo como coordenadas geográficas $8^{\circ} 31^{\prime} 16^{\prime \prime}$ de latitude sul e 36³3'0"de longitude oeste, com altitude de $650 \mathrm{~m}$. A precipitação pluviométrica média da região é de 629,9 mm por ano e está concentrada nos meses de março a julho (aproximadamente $60 \%$ do volume total anual). As temperaturas mais elevadas ocorrem nos meses de novembro a janeiro e são superiores a $30^{\circ} \mathrm{C}$; a média mensal varia de 21,7 a $25^{\circ} \mathrm{C}$ e a mínima, de 15,7 a $15,2^{\circ} \mathrm{C}$. A unidade relativa do ar é, em média, de 66\% (FIDEPE, 1982).

Foram utilizadas cinco vacas holandesas em lactação (aos 50 dias de lactação) com peso vivo (PV) médio de $645 \mathrm{~kg}$. Os animais foram alojados em baias individuais, com cerca de arame farpado e piso de terra batida, com área coberta de $3 \mathrm{~m}^{2}$, dotadas de cocho para fornecimento e controle do consumo de alimentos e bebedouro para fornecimento de água (à vontade).

Os animais foram distribuídos em quadrado latino $5 \times 5$, cinco animais, cinco níveis de caroço de algodão $(0,00$; 6,$25 ; 12,50 ; 18,75$ e 25,00\% na MS da dieta) e cinco períodos experimentais. Cada período teve duração de $17 \mathrm{dias,} \mathrm{dez}$ para adaptação dos animais às dietas e sete para coleta dos

Tabela 1 - Composição química dos ingredientes das dietas Table 1 - Chemical composition of ingredients of the experimental diets

\begin{tabular}{|c|c|c|c|c|c|}
\hline $\begin{array}{l}\text { Nutriente } \\
\text { Nutrient }\end{array}$ & $\begin{array}{c}\text { Palma } \\
\text { Forage cactus }\end{array}$ & $\begin{array}{l}\text { Silagem de sorgo } \\
\text { Sorghum silage }\end{array}$ & $\begin{array}{c}\text { Caroço de algodão } \\
\text { Whole cottonseed }\end{array}$ & $\begin{array}{c}\text { Farelo de soja } \\
\text { Soybean meal }\end{array}$ & $\begin{array}{c}\text { Fubá de milho } \\
\text { Corn meal }\end{array}$ \\
\hline $\operatorname{MS}(\%)(D M)$ & 8,00 & 26,51 & 92,6 & 88,86 & 86,47 \\
\hline $\mathrm{MO}^{1}(O M)$ & 90,50 & 95,03 & 96,4 & 94,18 & 98,71 \\
\hline $\mathrm{PB}^{1}(C P)$ & 5,09 & 6,26 & 21,03 & 51,24 & 10,07 \\
\hline $\mathrm{PIDN}^{1}(N D I C P)$ & 1,75 & 2,01 & 1,93 & 2,17 & 1,67 \\
\hline $\mathrm{PIDA}^{1}(A D I C P)$ & 0,58 & 1,15 & 1,59 & 1,53 & 0,86 \\
\hline $\mathrm{EE}^{1}$ & 1,94 & 1,78 & 21,20 & 2,94 & 4,21 \\
\hline $\mathrm{CT}^{1}(T C)$ & 83,47 & 86,99 & 57,17 & 40,00 & 84,43 \\
\hline $\mathrm{CNFcp}^{1}$ (NFCap) & 55,81 & 12,70 & 9,20 & 32,21 & 75,31 \\
\hline FDNcp $^{1}$ (NDFap) & 27,67 & 74,28 & 44,97 & 7,79 & 9,05 \\
\hline $\operatorname{FDA}^{1}(A D F)$ & 22,31 & 49,83 & 33,32 & 5,12 & 3,19 \\
\hline Lignina $^{1}$ (Lignin) & 5,20 & 7,80 & 10,12 & 1,99 & 1,44 \\
\hline $\mathrm{NDT}_{1 \mathrm{x}}{ }^{1}(T D N)$ & 65,56 & 51,00 & 84,33 & 82,16 & 84,15 \\
\hline $\mathrm{Ca}^{1}$ & 2,25 & 0,46 & 0,70 & 0,35 & 0,05 \\
\hline $\mathrm{P}^{1}$ & 0,28 & 0,36 & 0,73 & 0,60 & 0,30 \\
\hline $\mathrm{K}^{1}$ & 1,10 & 1,04 & 0,65 & 2,26 & 0,31 \\
\hline $\mathrm{Na}^{1}$ & 0,10 & 0,15 & 0,08 & 0,04 & 0,02 \\
\hline $\mathrm{Mg}^{1}$ & 1,07 & 0,59 & 0,75 & 0,67 & 0,20 \\
\hline
\end{tabular}

FDNcp = fibra em detergente neutro corrigida para cinza e proteína; $C N F c p=$ carboidratos não-fibrosos corrigidos para cinza e proteína; NDT $_{1 \mathrm{X}}=$ nutrientes digestíveis totais em nível de mantença estimados pelo NRC $(2001) ;{ }^{1}=\%$ na MS.

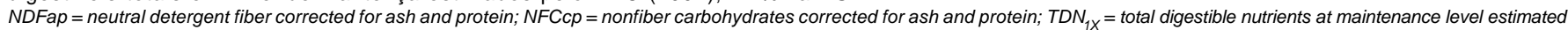
from the NRC (2001); ${ }^{1}=\%$ of DM 
dados e das amostras. O arraçoamento foi feito três vezes ao dia, na forma de mistura completa, permitindo sobras de 5 a $10 \%$ do total da MS fornecida. Durante os sete dias do período de coleta, as sobras foram recolhidas pela manhã, antes do primeiro arraçoamento, sendo pesadas e processadas ao final de cada período para formação de uma amostra composta por tratamento e por período.

Nas Tabelas 1 e 2 são apresentadas, respectivamente, as composições dos ingredientes e das dietas, de acordo com os níveis de caroço de algodão em substituição à silagem de sorgo e ao farelo de soja (Tabela 2).

Durante o período de coleta, amostras spot de urina foram obtidas no 11 o dia de cada período experimental, aproximadamente 4 horas após a alimentação, durante micção espontânea. Uma alíquota de $10 \mathrm{~mL}$ foi diluída em $40 \mathrm{~mL}$ de ácido sulfúrico de normalidade 0,036. Em seguida, o $\mathrm{pH}$ foi aferido e, se necessário, ajustado para valores inferiores a 3, com pequenas gotas de ácido sulfúrico concentrado, a fim de evitar destruição bacteriana dos derivados de purina e precipitação do ácido úrico. As amostras de urina foram armazenadasa $-20^{\circ} \mathrm{C}$ e, posterior- mente, submetidas a análises das concentrações de creatinina, uréia, alantoína e ácido úrico.

Na mesma ocasião, foram coletadas amostras de sangue de cada animal, por punção da veia jugular, aplicando-se como anticoagulante três gotas de heparina em cada tubo de ensaio. As amostras foram imediatamente centrifugadas a $5.000 \mathrm{rpm}$ durante 15 minutos e o plasma resultante foi armazenado a $-20^{\circ} \mathrm{C}$ para posterior análise das concentrações de uréia.

A produção de leite foi pesada diariamente nas três ordenhas diárias, durante todo o período experimental, no entanto, para a análise experimental,considerou-se apenas a produção média dos sete dias do período de coleta. Amostras de leite proporcionais às três ordenhas de cada animal foram coletadas nos $14^{\circ}$ e $15^{\circ}$ dias de cada período experimental e imediatamente submetidas à análise do teor de gordura e ao cálculo da produção de leite corrigida para $3,5 \%$ de gordura, proporcional a cada ordenha. Uma alíquota de $10 \mathrm{~mL}$ de leite foi misturada com $5 \mathrm{~mL}$ de ácido tricloroacético a $25 \%$, filtrado em papel-filtro e armazenada a $-20^{\circ} \mathrm{C}$ para análises de uréia e alantoína.

Tabela 2 - Composição química das dietas

Table 2 - Ingredient and chemical composition of the experimental diets

Ingrediente (\% da MS da dieta total)

Ingredient (\% diet $D M$ )

Nível de caroço de algodão (\%) Whole cottonseed level

\begin{tabular}{|c|c|c|c|c|c|}
\hline & \\
\hline & 0,00 & 6,25 & 12,50 & 18,75 & 25,00 \\
\hline Palma (Forage cactus) & 28,92 & 29,46 & 29,21 & 28,74 & 29,29 \\
\hline Silagem sorgo (Sorghum silage) & 27,27 & 23,68 & 19,54 & 15,84 & 12,13 \\
\hline Caroço algodão (Whole cottonseed) & 0,00 & 6,25 & 12,72 & 19,39 & 25,43 \\
\hline Farelo de soja (Soybean meal) & 23,88 & 20,90 & 18,66 & 16,08 & 13,27 \\
\hline Fubá milho (Corn meal) & 18,91 & 18,70 & 18,86 & 18,93 & 18,58 \\
\hline Mistura mineral (Mineral mix) & 1,02 & 1,01 & 1,02 & 1,02 & 1,01 \\
\hline
\end{tabular}

Composição químico-bromatológica

Chemical composition

\begin{tabular}{|c|c|c|c|c|c|}
\hline $\operatorname{MS}(\%)(D M)$ & 19,45 & 19,46 & 20,14 & 20,36 & 20,83 \\
\hline $\mathrm{MO}^{1}(O M)$ & 93,24 & 93,33 & 93,46 & 93,58 & 93,66 \\
\hline $\mathrm{PB}^{1}(C P)$ & 17,30 & 16,89 & 16,85 & 16,68 & 16,29 \\
\hline $\operatorname{PIDN}^{1}(N D I C P)$ & 1,89 & 1,88 & 1,86 & 1,86 & 1,84 \\
\hline $\operatorname{PIDA}^{1}(A D I C P)$ & 1,00 & 1,02 & 1,04 & 1,06 & 1,07 \\
\hline $\mathrm{EE}^{1}$ & 2,25 & 3,73 & 4,97 & 6,24 & 7,38 \\
\hline $\mathrm{CT}^{1}(T C)$ & 73,69 & 72,71 & 71,64 & 70,66 & 69,99 \\
\hline $\mathrm{CNFcp}^{1}$ (NFCap) & 41,54 & 40,84 & 40,17 & 39,27 & 38,66 \\
\hline FDNcp $^{1}$ (NDFap) & 31,83 & 31,87 & 31,49 & 31,40 & 31,35 \\
\hline $\mathrm{FDA}^{1}(A D F)$ & 22,58 & 22,67 & 22,60 & 22,67 & 22,72 \\
\hline Lignina $^{1}$ (Lignin) & 4,38 & 4,70 & 4,97 & 5,28 & 5,57 \\
\hline $\mathrm{NDT}_{1 \mathrm{X}}{ }^{1}(T D N)$ & 68,40 & 69,57 & 71,04 & 72,41 & 73,36 \\
\hline $\mathrm{Ca}^{1}$ & 1,31 & 1,31 & 1,27 & 1,29 & 1,33 \\
\hline $\mathrm{P}^{1}$ & 0,50 & 0,54 & 0,54 & 0,58 & 0,63 \\
\hline $\mathrm{K}^{1}$ & 1,20 & 1,14 & 1,08 & 1,03 & 0,97 \\
\hline $\mathrm{Na}^{1}$ & 0,29 & 0,29 & 0,29 & 0,29 & 0,29 \\
\hline $\mathrm{Mg}^{1}$ & 0,66 & 0,68 & 0,68 & 0,69 & 0,70 \\
\hline
\end{tabular}

FDNcp = fibra em detergente neutro corrigida para cinzas e proteína; CNFcp = carboidratos não-fibrosos corrigidos para cinzas e proteína; NDT1x = nutrientes digestíveis totais em nível de mantença estimados pelo NRC $(2001) ;{ }^{1}=\%$ na MS.

$N D F a p=$ neutral detergent fiber corrected for ash and protein; $N D F f=$ neutral detergent fiber of the sorghum silage; $N F C_{a p}=$ nonfiber carbohydrates corrected for ash and protein; $T D N_{1 x}=$ total digestible nutrients at maintenance level estimated from the NRC (2001); ${ }^{1}=\%$ DM 
Os níveis de uréia no plasma, na urina e no leite desproteinado e as concentrações de creatinina na urina e ácido úrico na urina foram determinados utilizando-se kits comerciais (Labtest), segundo orientações do fabricante. As análises de alantoína na urina e no leite desproteinado foram feitas pelo método colorimétrico, proposto por Fugihara et al (1987), descrito por Chen \& Gomes (1992).

O volume urinário foi estimado para cada animal multiplicando-se o respectivo PV pela excreção diária de creatinina ( $\mathrm{mg} / \mathrm{kg}$ de $\mathrm{PV}$ ) e dividindo-se esse produto pela concentração de creatinina $(\mathrm{mg} / \mathrm{L})$ na amostra spot. Para determinação da excreção diária de creatinina por kg de PV, foi adotada uma média ( $25 \mathrm{mg} / \mathrm{kg}$ PV) dos experimentos realizados por Silva et al. (2001), Oliveira et al. (2001) e Valadares et al. (1999).

A excreção total de derivados de purina (DP) foi calculada como a soma das quantidades de alantoína excretada na urina e no leite e a excreção de ácido úrico na urina, expressos em mmol/dia.

As purinas absorvidas (PA) (X,mmol/dia) foram calculadas a partir da excreção de derivados de purina (Y, mmol/ dia), por meio da equação $X=\left\{Y-\left(0,385 \times \mathrm{PV}^{0,75}\right)\right\} / 0,85$, em que 0,85 é a recuperação de purinas absorvidas como DP e 0,385 PV0,75, a contribuição endógena para a excreção de purinas (Verbic et al., 1990).

A síntese ruminal de nitrogênio ( $\mathrm{Y}, \mathrm{gN} / \mathrm{dia}$ ) foi calculada em função das PA (X, mmol/dia), utilizando-se uma modificação da equação descrita por Chen \& Gomes (1992), substituindo-se a relação Npurina:Ntotal nas bactérias de 0,116 por 0,134 , conforme descrito por Valadares et al. (1999):

$$
\mathrm{Y}=70 \mathrm{X} / 0,83 \times 0,134 \times 1000,
$$

em que 70 é o nitrogênio de purinas ( $\mathrm{mgN} / \mathrm{mol}) ; 0,134$, a relação $\mathrm{N}$ purina: $\mathrm{N}$ total das bactérias; e 0,83 , a digestibilidade das purinas microbianas.

A eficiência da síntese de nitrogênio microbiano (ESNmic) foi calculada pela quantidade de Nmic sintetizado pelo consumo de matéria orgânica aparentemente digerida no rúmen (CMODR):

ESNmic $(\mathrm{g} / \mathrm{kg})=$ SNmic $(\mathrm{g}) / \mathrm{CMODR}(\mathrm{kg})$, em que $\mathrm{CMODR}=\mathrm{CMO} \times 0,65(\mathrm{ARC}, 1990)$ e $\mathrm{CMO}=$ consumo de MO digestível. A estimativa de PB microbiana (EPBmic) foi obtida multiplicando-se a SNmic por 6,25, enquanto a eficiência de síntese de proteína microbiana foi determinada pela fórmula: EPBmic $(\mathrm{g} / \mathrm{kg})=$ SPBmic $(\mathrm{g}) /$ CNDT $(\mathrm{kg})$, em que CNDT = consumo de nutrientes digestíveis totais.

Os dados foram submetidos às análises de variância e regressão utilizando-se o sistema de Análises Estatísticas e Genéticas - SAEG (UFV, 1998). Os critérios utilizados na escolha do modelo foram a significância dos coeficientes de regressão e o coeficiente de determinação $\left(\mathrm{r}^{2}\right)$, obtido pela relação entre a soma dos quadrados da regressão e a soma de quadrados dos tratamentos.

\section{Resultados e Discussão}

Como demonstrado na Tabela 3, ao incluir caroço de algodão na dieta de vacas em lactação, os consumos de MS, MO e NDT e a produção de leite corrigida para 3,5\% de gordura (PLCG) aumentaram linearmente. O consumo de matéria orgânica digerida no rúmen (MODR), a produção de leite não corrigida (PL) e o teor de gordura do leite (GL) não foram influenciados pelos níveis de substituição da silagem de sorgo e farelo de soja por caroço de algodão (CA).

Não houve efeito dos tratamentos sobre a estimativa do volume urinário, as excreções urinárias diárias de creatinina, ácido úrico, alantoína, alantoína total, purinas totais e purinas absorvidas e a síntese de nitrogênio microbiano e PB microbiana (Tabela 4). A secreção de alantoína no leite apresentou efeito linear crescente, com aumento de $0,13 \mathrm{mg} / \mathrm{dL}$ para cada $1 \%$ de caroço de algodão incluído na dieta.

O volume urinário estimado pelo indicador metabólico creatinina não foi influenciado pela inclusão do caroço de algodão na dieta, cujo valor médio foi de $23,94 \mathrm{~L} /$ dia. Segundo o NRC (2001), as perdas de água pelo animal ocorrem principalmente pela produção de leite, pelas perdas fecais e pelas perdas urin árias. As perdas pelo leite e pelas fezes são similares, próximas a $35 \%$ da ingestão total de água, respectivamente, enquanto a perda pela urina corresponde à metade das perdas fecais e varia de 15 a $21 \%$ em vacas em lactação. Segundo Holter \& Huban (1992), a excreção de água em vacas produzindo $34,6 \mathrm{~kg}$ de leite/dia é de 4,5 a 35,4 L/dia. Portanto, o volume urinário estimado neste experimento ficou entre os valores médios citados e próximo aos valores estimados de excreção pela urina, de $21 \%$ do consumo total de água preconizado pelo NRC (2001).

$\mathrm{O}$ requerimento de água pelos animais, estimado por meio da equação de Murphy et al. (1993), citados pelo NRC (2001), seria de 110,70 kg/dia, o que leva à estimativa de excreção diária de urina de 18,82 e 23,25 L/dia para os valores de 17 e $21 \%$ das perdas totais de água preconizadas. Portanto, esses valores creditam o indicador creatinina para estimativa segura do volume urinário.

A excreção de derivados de purina, representada nos bovinos por alantoína e ácido úrico, não foi influenciada estatisticamente pelos níveis de caroço de algodão na dieta. 
Tabela 3 - Consumos médios diários de MS, MO, MO digerida no rúmen (CMODR), PB e NDT, produção de leite (PL), produção de leite corrigida para o 3,5\% de gordura (PLCG), porcentagem de gordura do leite (GL), coeficientes de variação (CV), equações de regressão ajustadas $(E R)$ e nível de probabilidade $(P)$ referente aos efeitos linear $(L)$ e quadrático $(Q)$ dos níveis de caroço de algodão (CA) na dieta

Table 3 - $\quad$ Average daily intakes of DM(DMI), OM (OMI), OM digested in the rumen (OMDRI), CP (CPI), TDN (TDNI), milk production (MP), 3.5\% fat corrected milk (FCM) and milk fat percentage (MFP), coefficient of variation (CV), fitted regression equations (RE) and level of probability ( $P$ ) of linear ( $L$ ) and quadratic (Q) effects according to different levels of whole cottonseed (WC) in the diet

\begin{tabular}{|c|c|c|c|c|c|c|c|c|c|}
\hline & \multicolumn{5}{|c|}{$\begin{array}{c}\text { Nível de caroço de algodão }(\%) \\
\text { Whole cottonseed level }(\%)\end{array}$} & \multirow[t]{2}{*}{$\mathrm{CV}(\%)$} & \multirow[t]{2}{*}{$\begin{array}{l}\mathrm{ER} \\
R E\end{array}$} & \multicolumn{2}{|c|}{$\mathrm{P}$} \\
\hline & 0,00 & 6,25 & 12,50 & 18,75 & 25,00 & & & $\mathrm{~L}$ & Q \\
\hline $\begin{array}{l}\text { Consumo de MS (kg/dia) } \\
\text { DM intake ( } k g / \text { day) }\end{array}$ & 21,43 & 21,38 & 22,03 & 24,27 & 23,50 & 6,32 & 1 & 0,02 & NS \\
\hline $\begin{array}{l}\text { Consumo de MO (kg/dia) } \\
\text { OM intake ( } k g / \text { day) }\end{array}$ & 20,24 & 18,35 & 20,67 & 22,61 & 22,07 & 8,84 & 2 & 0,00 & NS \\
\hline $\begin{array}{l}\text { Consumo de MODR (kg/dia) } \\
\text { OMDR intake ( } \mathrm{kg} / \text { day) }\end{array}$ & 9,17 & 9,33 & 9,45 & 10,23 & 9,86 & 8,08 & $\hat{\mathrm{y}}=9,61$ & NS & NS \\
\hline $\begin{array}{l}\text { Consumo de PB (kg/dia)) } \\
\text { CP intake ( } k g / \text { day }\end{array}$ & 3,88 & 3,73 & 3,73 & 3,95 & 3,72 & 6,92 & $\hat{\mathrm{y}}=3,80$ & NS & NS \\
\hline $\begin{array}{l}\text { Consumo de NDT (kg/dia) } \\
\text { TDN intake ( } k g / \text { day) }\end{array}$ & 14,51 & 15,14 & 15,78 & 17,13 & 16,76 & 8,32 & 3 & 0,00 & NS \\
\hline PL (kg/dia) & 29,5 & 30,24 & 31,25 & 32,67 & 32,27 & 10,84 & $\hat{\mathrm{y}}=31,19$ & NS & NS \\
\hline $\begin{array}{l}M P(k g / \text { day }) \\
\text { PLCG (kg/dia) } \\
F C M \quad(k g / \text { day })\end{array}$ & 26,7 & 28,12 & 30,22 & 30,74 & 31,68 & 8,67 & 4 & 0,01 & NS \\
\hline $\begin{array}{l}\mathrm{GL}(\%) \\
\operatorname{MFP}(\%)\end{array}$ & 2,91 & 3,15 & 3,33 & 3,13 & 3,39 & 10,4 & $\hat{y}=3,18$ & NS & NS \\
\hline
\end{tabular}

NS = não-significativo (not significant).

$1=\hat{\mathrm{y}}=21,11+0,11 \mathrm{CA} \quad \mathrm{r}^{2}=0,73 ; \quad 2=\hat{\mathrm{y}}=19,20+0,12 \mathrm{CA} \quad \mathrm{r}^{2}=0,56$

$3=\hat{y}=14,57+0,10 \mathrm{CA} \quad \mathrm{r}^{2}=0,88 ; \quad 4=\hat{\mathrm{y}}=26,98+0,20 \mathrm{CA} \quad \mathrm{r}^{2}=0,96$.

Tabela 4 - Volume urinário estimado (VUE), excreção urinária de creatinina (CRu), ácido úrico (AUu), alantoína (ALu), alantoína no leite $(A L I)$, alantoína total (ALt), excreção de derivados de purina total (EDPt), purinas absorvidas (Pa) e sínteses de nitrogênio microbiano (SNmic) e proteína microbiana (SPBmic), coeficientes de variação (CV), equações de regressão ajustadas (ER) e nível de probabilidade referente aos efeitos linear e quadrático dos níveis de caroço de algodão

Table 4 - Average estimate of urine volume (UVE), urinary creatinine excretion (UCRE), urinary uric acid ( $U$ UAE), and urinary allantoin (UALE), milk allantoin ( $m A L)$, total allantoin (tAL), total purine derivatives excretion (tPDE), purine absorbed (Pa), and synthesis of microbial nitrogen (SmicN) and microbial protein I(SmicCP), coefficients of variation (CV), fitted regression equations $(R E)$ and level of probability $(P)$ of linear $(L)$ and quadratic $(Q)$ effects according to different levels of whole cottonseed (WC) in the diet

\begin{tabular}{|c|c|c|c|c|c|c|c|c|c|}
\hline & \multicolumn{5}{|c|}{$\begin{array}{c}\text { Nível de caroço de algodão (\%) } \\
\text { Whole cottonseed level }(\%)\end{array}$} & \multirow[t]{2}{*}{$\mathrm{CV}(\%)$} & \multirow[t]{2}{*}{$\begin{array}{l}\mathrm{ER} \\
R E\end{array}$} & \multicolumn{2}{|c|}{$\mathrm{P}$} \\
\hline & 0,00 & 6,25 & 12,50 & 18,75 & 25,00 & & & $\mathrm{~L}$ & Q \\
\hline $\operatorname{VUE}(\mathrm{L})^{1}(U V E)$ & 23,88 & 22,70 & 23,67 & 25,06 & 24,35 & 27,83 & $\hat{y}=23,94$ & NS & NS \\
\hline $\mathrm{CRu}(\mathrm{mg} / \mathrm{dL})(u C R E)$ & 71,21 & 83,67 & 77,85 & 60,76 & 78,87 & 34,85 & $\hat{y}=74,07$ & NS & NS \\
\hline $\mathrm{AUu}(\mathrm{mmol})^{1}(u U A E)$ & 33,16 & 37,07 & 26,33 & 29,94 & 41,14 & 38,70 & $\hat{y}=33,53$ & NS & NS \\
\hline $\mathrm{ALu}(\mathrm{mmol})^{1}(u A L)$ & 396,74 & 461,05 & 389,86 & 395,86 & 353,59 & 18,35 & $\hat{y}=399,47$ & NS & NS \\
\hline $\operatorname{ALl}(\mathrm{mmol})^{1}(m A L)$ & 12,93 & 13,23 & 15,31 & 16,00 & 15,70 & 14,64 & 1 & 0,01 & NS \\
\hline $\operatorname{ALt}(\mathrm{mmol})^{1}(t A L)$ & 409,67 & 474,31 & 405,07 & 411,55 & 369,29 & 18,02 & $\hat{y}=414,00$ & NS & NS \\
\hline $\operatorname{EDPt}(\mathrm{mmol})^{1}(t P D E)$ & 447,92 & 511,39 & 431,51 & 441,44 & 419,44 & 18,22 & $\hat{y}=448,55$ & NS & NS \\
\hline $\mathrm{Pa}(\mathrm{mmol})^{1}(\mathrm{~Pa})$ & 468,00 & 543,06 & 449,08 & 460,82 & 424,30 & 20,49 & $\hat{y}=469,13$ & NS & NS \\
\hline $\operatorname{SNmic}(\mathrm{g})^{1}($ SmicN $)$ & 294,58 & 341,58 & 282,47 & 289,85 & 266,88 & 20,49 & $\hat{y}=295,08$ & NS & NS \\
\hline $\operatorname{SPBmic}(\mathrm{g})^{1}(\operatorname{Smic} C P)$ & 1841,35 & 2134,87 & 1765,43 & 1811,56 & 1668,00 & 21,37 & $\hat{\mathrm{y}}=1844,27$ & NS & NS \\
\hline
\end{tabular}

NS = não-significativo (not significant)

1 por dia (per day).

$1=\hat{\mathrm{y}}=12,98+0,13 \mathrm{CA} \quad \mathrm{r}^{2}=0,83$. 
Foram obtidos valores médios de excreção na urina de 399,47 e 33,53 mmol/dia e de 411,25 e 447,79 mmol/dia de excreção de alantoína total e derivados de purina total, respectivamente.

A excreção de ácido úrico e alantoína na urina corresponderam a 7,48 e $89,05 \%$ do total de derivados de purina, valores próximos aos citados por Chen \& Gomes (1995), de 15 a $20 \%$ e de 80 a $85 \%$ do total excretado na urina de bovinos em relação ao total de derivados de purina para eficiência de síntese de nitrogênio microbiano de 32 g/kgCMODR (ARC, 1990). Portanto, esta amplitude de excreção de ácido úrico e alantoína na urina em relação aos DP fica condicionada ao estádio fisiológico do animal e aos tratamentos dietéticos (Johnson et al., 1998).

Não se constatou efeito significativo para a absorção de purinas e a síntese de nitrogênio e PB microbiana, fato previsto, pois estas variáveis são estimadas a partir da excreção de DP. Portanto, as dietas consumidas pelos animais parecem ter sido eficientes em termos de quantidade e sincronização de disponibilidade de proteína:energia e favorecimento do ambiente ruminal, pois afetaram a quantidade e o tipo de gordura no crescimento microbiano, fatores que, segundo Clark et al. (1992) e Jenkins (1993), seriam os principais limitantes da síntese de nitrogênio microbiano. No entanto, existem variáveis que podem ser correlacionadas à eficiência de utilização da proteína dietética pelos microrganismos do rúmen e ao animal.

Na Tabela 5, encontram-se as médias referentes à estimativa das eficiências da síntese de nitrogênio microbiano (ESMmic) e proteína bruta microbiana (ESPBmic), uréia na urina, uréia no plasma, $\mathrm{N}$-uréia no plasma, uréia no leite, $\mathrm{N}$-uréia no leite.
Com a inclusão de caroço de algodão na dieta de vacas em lactação, as ESNmic e ESPBmic diminuíram linearmente, com valores máximos e mínimos de 36,61 e 27,06 g Nmic/kg CMODR e de 140,81 e 99,66 g PBmic/kg CNDT, respectivamente. Esse efeito provavelmente foi reflexo da ausência de significância da SNmic e Pbmic, do aumento do consumo de NDT e da tendência de aumento no consumo de CMODR. As demais variáveis estudadas não foram afetadas pelos níveis de caroço de algodão na dieta.

As ESNmic e ESPBmic diminuíram 0,30 e 1,43 g para cada $1 \%$ de CA incluído na dieta. Provavelmente, esta menor eficiência esteja relacionada à disponibilidade de proteína degradada no rúmen (PDR), pois o consumo de PB não foi influenciado pelos níveis de CA, com valor médio de 3,80 $\mathrm{kg} /$ dia (Tabela 3), decorrente do teor decrescente de PB nos tratamentos experimentais (Tabela 2) e da possível seleção realizada pelos animais.

Apesar da diferença nos teores de PB entre as dietas (Tabela 2), a PDR estimada a partir dos valores tabelados pelo NRC (2001) manteve-se constante em todos os tratamentos, com média de $10,05 \%$, o que pode ter anulado a influência sobre SPBmic, com média de síntese (Tabela 4) de $1.844,27 \mathrm{~g} /$ dia. Utilizando a eficiência de conversão da PDR de 1,18 citada pelo NRC (2001), obtém-se captação de PDR pelos microrganismos de $2.176,24 \mathrm{~g} / \mathrm{dia}$, que corresponde a aproximadamente $9,71 \%$ de captação da PDR observada neste experimento.

A hipótese de que a disponibilidade de PDR teve efeito negativo na ESPBmic baseia-se na ausência de significância para as demais variáveis estudadas, diretamente relaciona-

Tabela 5 - Eficiência de síntese de nitrogênio microbiano (ESNmic) e PB microbiana (ESPBmic), concentrações de uréia na urina (CUu), de uréia (CUp) e de nitrogênio uréia no plasma (CNUp), de uréia no leite (CUI) e de nitrogênio uréia no leite (CNUI), coeficientes de variação $(C V)$, equações de regressão ajustadas $(E R)$ e nível de probabilidade $(P)$ referente aos efeitos linear $(L)$ e quadrático (Q), em função dos níveis de caroço de algodão na dieta

Table 5 - Average efficiencies of microbial nitrogen (ESmicN) and microbial crude protein (ESmicCP) synthesis, concentrations of urinary of urea (CuU), plasma urea (Cup), plasma urea $N(C U N p)$, milk urea (CmU), milk urea nitrogen (CmUN), coefficients of variation (CV), fitted regression equations $(R E)$ and level of probability $(P)$ of linear $(L)$ and quadratic $(Q)$ effects according to different levels of whole cottonseed (WC) in the diet

\begin{tabular}{|c|c|c|c|c|c|c|c|c|c|}
\hline & \multicolumn{5}{|c|}{$\begin{array}{c}\text { Nível de caroço de algodão (\%) } \\
\text { Whole cottonseed level }\end{array}$} & \multirow[t]{2}{*}{$\mathrm{CV}(\%)$} & \multirow[t]{2}{*}{$\begin{array}{l}\mathrm{ER} \\
R E\end{array}$} & \multicolumn{2}{|c|}{$P$} \\
\hline & 0,00 & 6,25 & 12,50 & 18,75 & 25,00 & & & $\mathrm{~L}$ & Q \\
\hline ESNmic (g) (ESmicN) & 32,45 & 36,61 & 29,65 & 28,36 & 27,06 & 19,02 & 1 & 0,04 & NS \\
\hline ESPBmicr $(\mathrm{g})($ ESmic $C P)$ & 128,01 & 140,81 & 111,12 & 105,92 & 99,66 & 18,84 & 2 & 0,01 & NS \\
\hline $\mathrm{CUu}(\mathrm{mg} / \mathrm{kgPV})(\mathrm{CuU})$ & 495,24 & 519,07 & 381,51 & 522,19 & 419,21 & 40,52 & $\hat{y}=467,45$ & NS & NS \\
\hline $\mathrm{CUp}(\mathrm{mg} / \mathrm{dL})(C U p)$ & 29,25 & 27,32 & 27,42 & 27,67 & 27,80 & 10,20 & $\hat{\mathrm{y}}=27,89$ & NS & NS \\
\hline CNUp (mg/dL) (CUNp) & 13,63 & 12,73 & 12,77 & 12,89 & 12,95 & 10,20 & $\hat{y}=12,99$ & NS & NS \\
\hline CUl (mg/dL) $(\mathrm{CmU})$ & 9,96 & 10,98 & 9,39 & 10,76 & 11,29 & 19,63 & $\hat{y}=10,51$ & 0,01 & NS \\
\hline CNUl $(\mathrm{mg} / \mathrm{dL})(\mathrm{Cm} U N)$ & 4,64 & 5,16 & 4,46 & 5,01 & 5,26 & 19,63 & $\hat{\mathrm{y}}=4,90$ & NS & NS \\
\hline
\end{tabular}

NS $=$ não-significativo (not significant).

$1={ }_{\text {^ }}=34,6337-0,30 \mathrm{CA} \quad \mathrm{r}^{2}=0,63 ; 2=$. $=135,42-1,43 \mathrm{CA} \quad \mathrm{r}^{2}=0,731$ 
das à eficiência de utilização da proteína e à sincronização energia:proteína.

A excreção de uréia na urina $(467,45 \mathrm{mg} / \mathrm{kgPV})$ não foi influenciada pela inclusão de caroço de algodão na dieta, o que indica possível constância no aproveitamento dietético da proteína pelos animais, visto que o aumento da ingestão de energia (Tabela 3 ) não ocasionou diminuição da excreção de uréia na urina.

As concentrações de uréia e N-uréia no plasma não foram influenciadas pela inclusão de caroço de algodão na dieta, cujos valores médios foram de 27,89 e $12,99 \mathrm{mg} / \mathrm{dL}$, respectivamente. Esta resposta pode ser atribuída ao fato de as dietas experimentais apresentarem a mesma concentração de PDR e de a concentração de uréia no plasma ser diretamente relacionada à eficiência de utilização do nitrogênio disponível aos microrganismos. Esta eficiência depende da sincronização da disponibilidade de proteína e energia para que as bactérias capturem a maior parte da amônia liberada no rúmen. Contudo, quando em algumas situações a taxa de liberação excede a taxa de captação, verifica-se aumento de uréia e N-uréia no plasma (NRC, 2001).

Os valores de uréia e $\mathrm{N}$-uréia no plasma observados neste experimento estão dentro da faixa de variação encontrada na literatura, como os valores obtidos por Silva et al. (2001), de 46,23 e 21,59 mg/dL; Oliveira et al. (2001), de 35,52 a 49,52 e de 23,08 a 16,43 mg/dL; e Cruz (2002), de 31,37 e 14,62 mg/dL, respectivamente. Valadares et al. (1999), no entanto, encontraram valores de 22,8 a $17,3 \mathrm{mg} / \mathrm{dL}$ para concentração de uréia no plasma, com resposta quadrática relativa ao nível de concentrado na dieta. O nível ótimo de produção microbiana foi obtido com $35,4 \%$ de CNF e $21,7 \mathrm{mg} / \mathrm{dL}$ de uréia no plasma. Portanto, a concentração de uréia e $\mathrm{N}$-uréia no plasma depende da quantidade de proteína e energia dietética.

As concentrações médias de uréia e N-uréia no leite não foram influenciadas pelos níveis de caroço de algodão na dieta e apresentaram valores médios de 10,51 e 4,90 mg/ $\mathrm{dL}$, respectivamente, o que provavelmente foi ocasionado pela ausência de significância nas concentrações de uréia e N-uréia no plasma, pois, segundo Kauffman \& St-pierre (2001), citados por Cruz (2002), o aumento de amônia no rúmen eleva a concentração sangüínea de uréia e, conseqüentemente, sua difusão para o leite.

\section{Conclusões}

A inclusão de caroço de algodão em níveis de até $25 \%$ da matéria seca em substituição à silagem de sorgo e ao farelo de soja em dietas à base de palma forrageira para vacas holandesas em lactação não interfere na síntese de proteína microbiana e nas concentrações de uréia.

\section{Literatura Citada}

AGRICULTURAL RESEARCH COUNCIL - ARC. The nutrient requirement of ruminant livestock. Farnham Royal: Commonwealth Agricultural Bureaux, 1984. 45p.

AGRICULTURAL RESEARCH COUNCIL - ARC. The nutrient requerement of ruminant livestock. Farnham Royal: Commonwealth Agricultural Bureaux, 1990. 159p.

BRODERICK, G.A.; MERCHEN, N.R. Markers for quantifying microbial protein synthesis in the rumen. Journal of Dairy Science, v.75, p.2618-2632, 1992.

BRODERICK, G.A. Use of milk urea as indicator of nitrogen utilization in lactating dairy cow. Washington: U. S. Dairy Forage Center; U.S. Department of Agriculture, Agricultural Research Service, 1995. 122p. (Research Summaries.).

CHEN, X.B.; GOMES, M.J. Estimation of microbial protein supply to sheep and cattle based on urinary excretion of purine derivatives - an overview of technical details. Aberdeen: Rowett Research Institute/ International Feed Research Unit, 1992. 21p. (Occasional Publication).

CLARK, J.M.; KLUSMEYER, T.H.; CAMERON, M.R. et al. Microbial protein synthesis an flows of nitrogen factions to tue duodenum of dairy cows. Journal of Dairy Science, v.75, p.2304-2323, 1992.

CRUZ, M.C.S. Estimativas de perdas endógenas e balanço de nitrogênio em vacas lactantes alimentadas com níveis crescentes de uréia e mandioca. Recife: Universidade Federal Rural de Pernambuco, 2002. 73p. Dissertação (Mestrado em Zootecnia) - Universidade Federal Rural de Pernambuco, 2002.

FUNDAÇÃO DE INFORMAÇÕES PARA O DESENVOLVIMENTO DE PERNAMBUCO - FIDEPE. Monografias municipais. São Bento do Una, Recife, 1982. 80p.

HOLTER, J.B.; HURBAN, W.E. Water partitioning an intake in dry and lactating hlstein cows. Journal of Dairy Science, v.75, p.1472-1479, 1992.

JENKINS, T.C. Lipid metabolism in the rumen. Journal of Dairy Science, v.76, p.3851-3863, 1993.

JOHNSON, L.M.; HARRISON, J. H.; RILEY, R.E. et al. Estimation of the flow of microbial nitrogen to the duodenum using urinary uric acid or allantoin. Journal of Dairy Science, v.81, p.24082420, 1998

NATIONAL RESEARCH COUNCIL - NRC. Nutrient requirements of the dairy cattle. 7.ed. Washington: D.C.: National Academy Press, 2001. 363p.

O'CONNOR J.D.; SNIFFER, C.J.; FOX, D.G. et al. A net carbohydrate and protein system for evaluating cattle diets: IV predicting amino acid adequacy. Journal of Dairy Science, v.71, p.1295-1311, 1993.

OLIVEIRA, A.S.; VALADARES, R.F.D.; VALADARES FILHO, S.C. et al. Produção de proteína microbiana e estimativas das excreções de derivados de purinas e de uréia em vacas lactantes alimentadas com rações isoprotéicas contendo diferentes níveis de compostos nitrogenados não-protéicos. Revista Brasileira de Zootecnia, v.26, p.1621-1629, 2001.

ORSKOV, E.R.; MACLEOD, N.A. The determination of the minimal nitrogen excretion in steers and dairy cows and its physiological and practical implications. British Journal Nutrition, v.47, p.625-636, 1982.

PERES, J.F.; BALCELLS, J.; GUABA, J.A. et al. Determination of rumen microbial-nitrogen production in sheep: a comparison of urinary purine excretion with methods using ${ }^{15} \mathrm{~N}$ and purine bases as markers of microbial- nitrogen entering the duodenum. British Journal Nutrition, v.75, p.699-709, 1996. 
RENNÓ, L.N.; VALADARES, R.F.D.; LEÃO, M.I. et al. Estimativa da produção microbiaana pelos derivados de Purina na urina em novilhos. Revista Brasileira de Zootecnia, v.29, p.12231234, 2000.

ROSELER, D.K.; FERGUNSON, J.D.; SNIFFEN, C.J. et al. Dietary protein degradability effects on plasma and milk urea nitrogen and milk nonprotein nitrogen in Holstein. Journal of Dairy Science, v.76, p.525-534, 1993.

RUSSELL, J.B.; O'CONNOR, J.D.; FOX, D.G. et al. A net carbohydrate and protein system for evaluating cattle diets. 1 . Ruminal fermentation. Journal of Animal Science, v.70, p.3551-3561, 1992.

SILVA, R.M.N.; VALADARES, R.F.D.; VALADARES FILHO, S.C. et al. Uréia para vacas em lactação. 2. Estimativa do volume urinário, da produção microbiana e da excreção de uréia. Revista Brasileira de Zootecnia, v. 30, p.1948-1957, 2001.

UNIVERSIDADE FEDERAL DE VIÇOSA - UFV. SAEG- Sistema de análise estatística e genética. versão 8.0. Viçosa, MG, 1998. 150p. (manual do usuário).

VALADARES, R.F.D.; GONÇALVES, L.C.; SAMPAIO, I.B. et al. Níveis de proteínas em dietas de bovinos. 4. Concentrações de amônia ruminal e uréia plasmática e excreções de uréia e creatinina. Revista Brasileira de Zootecnia, v.26, p.1270$1278,1997$.
VALADARES, R.F.D.; BRODERICK, G.A.; VALADARES FILHO, S.C. et al. Effect of replacing alfalfa silage with high moisture corn on ruminal protein synthesis estimated from excretion of total purine derivatives. Journal of Dairy Science, v.82, p.2686-2699, 1999.

VERBIC, J.; CHEN, X.B.; CAMACLEOD, N.A. et al. Excretion of purine derivatives by ruminants. Effect of microbial nucleic acid infusion on purine derivatives excretion by steers. Journal of Agriculture Science, v.114, p.243-248, 1990.

VISEK, W.J. Ammonia metabolism, urea cycle capacity and their biochemical assessment. Nutricion Reviste, v.2799, p.273282, 1979. 